\title{
Why do companies in Cameroon resist to be financed through the financial market?
}

\author{
TCHAPDA WOUMKEP Mélissa Grace ${ }^{1}$, HIKOUATCHA Prince ${ }^{2}$, TONMO Simplice \\ Gael $^{3}$, BIDIAS MENIK Hans Patrick ${ }^{4}$
}

1,2,3,4 Department of finance, University of Dschang, Dschang, Cameroon

\begin{abstract}
This paper aims at explaining why in a context characterized by a huge need for financing, managers are still reluctant to an Initial Public Offering. For that purpose, the data are collected from 42 companies, through a questionnaire. A Principal Component Analysis supplemented by an estimation, were used. The results show that managers have a positive perception of the stock market, but consider very high the associated costs. They also reveal a weak financial culture and the unfavorable business environment.
\end{abstract}

Keywords: Initial Public Offering, financial market, reluctance.

\section{Introduction}

Since the beginning of its activities in 2001, the financial market of Cameroon has only three (03) listed companies ${ }^{1}$, out of the 93,969 listed by the INS ${ }^{2}$. However, African stock exchanges created shortly before or after, have a higher volume of activity. For comparison, at the end of 2016, Botswana Stock Exchange born in 1989 and Ghana Stock Exchange which started its activities in 1990, have respectively 44 and 34 listed companies. Similarly, Libyan Stock Exchange (2007), Rwanda Stock Exchange (2008) and Seychelles Securities Exchange (2012), have 07, 05 and 04 listed companies respectively. These volumes of activity remain, of course, very low compared to those of the oldest financial markets in Africa ${ }^{3}$ and other developing countries.

In general, the number of African financial markets has grown drastically since the early 1990s (Nkontchou et al, 2010). Before 1989, Africa had 8 stock exchanges (Ordera, 2012), 19 in 2007 (Yartey and Adjasi, 2007), 26 in 2008 (Afego, 2011) and 29 in 2017. However, this proliferation is far from being a fad, as the underlying economic issues are real and relevant (Bayala, 2002). Thus, N'dri

\footnotetext{
${ }^{1}$ The capital of these three companies is in considerable proportion held by the State, which is moreover the only shareholder that has decided to open up its share of the capital on the financial market.

${ }^{2}$ National Institute of Statistics in 2009.

${ }^{3}$ The Egyptian Exchange (1883), the Johannesburg Stock Exchange (1887) and the Nigerian Stock Exchange (1960) had a total of 833, 402 and 223 listed companies respectively at the end of 2016.
} 
and Aderomou (2011) support the idea that the emergence of these markets responds to the financing needs of economies in general and businesses in particular. They note that states and communities see it as an adequate means of mobilizing and efficiently allocating savings, while investors and businesses find it a means of investment and financing in line with unmet needs. More specifically, in Cameroon, the creation of the stock market was intended to complement the weaknesses of a banking system that was unable to mobilize the long-term resources needed to finance production. This is the main finding of the 2012 ILO (International Labor Office) survey of firms in Cameroon and confirmed by Mussoka (2013).

Theoretically, from Modigliani-Miller (1958) to Myers and Majluf (1984), reflections on the financing of investment, have mostly concluded that there is no optimal mode of financing. In the same line, the question of the choice of financing in companies remains omnipresent in every milieus in the world. Cameroonian businesses are no exception, as shown by the various INS reports (2009 and 2012) that point to the lack of financing as one of the handicaps to their development.

The limitation of self-financing as a traditional source of financing in the Cameroonian context has led companies to turn to banks which, in a context of excess of liquidity and credit rationing. The General Business Census (RGE) conducted by the INS in 2007 confirms this situation, which has been recurring for several years. In addition, the rationing of bank credit combined with the practice of high interest rates leads managers to turn to informal sources of financing (tontines, friends, family), which are even more restrictive because of the usurious rates charged ${ }^{4}$. The Cameroonian financial market was created in this context to provide a complementary solution to this thorny problem that negatively impacts the competitiveness of companies.

The main advantage of an IPO is access to external sources of financing (Pagano et al, 1998), which is less costly and less restrictive than traditional financing channels. In addition to solving problems of information asymmetry (Myers and Majluf, 1984), the IPO favors the diversification of financing possibilities, increases the mobility of capital and the notoriety of the firm.

However, despite the enormous need for corporate financing, the Cameroonian financial market has demonstrated its capacity to mobilize funds through several solicitations of both public and private, local and international issuers through its bond compartment. It has, for example, succeeded in the bond issued by the International Finance Corporation (IFC) of the CEMAC zone in December 2009. Indeed, the IFC having launched a bond issue for an amount of 20 billion FCFA, the DSX ${ }^{5}$ alone has mobilized 11 billion. In addition, the Cameroonian government successfully issued a CFAF 200 billion bond in 2010. The Cameroonian financial market also successfully issued a bond of the CUD (Douala Urban Community) for an amount of CFAF 7 billion in 2005, that of the DBCAS (Development Bank of Central African States) for an amount of CFAF 30 billion in 2010 and that of the Cameroonian State for an amount equal to CFAF 150 billion in 2014. The success of these operations suggests the existence of the financial resources necessary for the proper functioning of the financial market. With the dynamism of the bond compartment, the financial market shows itself capable of accomplishing its primary mission, even if the equity compartment is struggling to catch up.

Moreover, we also observe a mistrust of subsidiaries of several multinationals installed in Cameroon, which are listed on several African financial markets, but not in Cameroon, despite the availability of

\footnotetext{
${ }^{4}$ In Cameroon, loans are repaid at a minimum average interest rate of $10 \%$ excluding tax, which is a far cry from the $5.5 \%$ of the bond issue launched by the government.

${ }^{5}$ Douala Stock Exchange is the name of the financial market that existed in Cameroon before the merger with the Central African sub-regional financial center in 2017
} 
financial resources. This is the case of NESTLE, $\mathrm{BICI}^{6}, \mathrm{SG}^{7}$, TOTAL listed on the regional stock market (BRVM). One can particularly note the situation of ECOBANK which, in 2006, undertook a simultaneous multiple listing of its shares on three stock exchanges in West Africa ${ }^{8}$ (Ekpe, 2010). However, it is also present on Cameroonian territory but has remained unlisted until now. This lack of interest on the part of companies in the financial market raises many questions and simply shows that despite the many advantages of being listed, there are also constraints. Thus, what can explain the disenchantment of firms with the financial market in Cameroon? The purpose of this reflection is therefore to understand and explain the lack of dynamism of the stock market compared to a very active bond market.

To achieve this, and following this introduction, the rest of this article is organized into three additional sections. The first section presents factors internal to firms. The second section presents factors related to the financial market environment. The third section concludes and makes some suggestions.

\section{Internal factors in the reluctance of companies to go public.}

\subsection{A selective review of the literature on the factors determining IPOs}

At least three factors can be identified. First, business leaders do not always have a positive perception of the stock market. Indeed, Bayala (2002) reveals that, for some managers of Burkinabe companies, the stock market is perceived as useless, inadequate, complex, risky and even restrictive. The same result is obtained by N'Dri and Aderomou (2011) with a sample of unlisted firms in Benin.

Second, listing requirements fall into two categories. The first refers to transparency, imposed by the listing, which puts the firm's past and future performance at the forefront as a necessary condition for capital mobilization. The listing thus entails a loss of confidentiality for the issuing company due to the transparency requirement (Bernoussi, 2012). On this subject, Campbell (1979) shows that the loss of confidentiality has a dissuasive effect on the willingness of firms to raise funds on the financial markets. Moreover, according to Pagano et al, (1998), the disclosing role of the stock market forces the firm to reveal secret information that could affect its competitiveness, limiting any fraudulent behavior.

In addition, in Cameroon, the RGE in 2010 reveals that only $42.9 \%$ of the companies established there keep written accounts. Of these, only $31.1 \%$ have formal accounting, which leads to the preparation of a Statistical and Fiscal Declaration (SFD), for a total of only $13 \%$ of all these companies (Tchapga and Feudjo, 2016). Yet, among the conditions required to access the financial market in Cameroon is the obligation to present three years of certified annual accounts. This requirement can thus be a major obstacle for companies applying to be listed. In this perspective, Tchapga and Feudjo (2016), based on an analysis of 97 firms established in Cameroon, highlight the existence of a negative and significant relationship between the decision to go public and the loss of control on the one hand, and on the other hand with the attachment of the manager to the confidentiality of information concerning his firm.

The second requirement refers to the opening of the capital to the public. Indeed, for an issue to be considered as public, the market company generally requires that the shares be acquired by a minimum number of people. An IPO is therefore synonymous to opening up the share capital to new shareholders, which could lead to a loss of control by its former owners (Jacquillat 1994, Grimblatt

\footnotetext{
${ }^{6}$ Present in Cameroon under the name of BICEC

${ }^{7}$ Present in Cameroon under the name "Société Générale Cameroun" (SGC)

${ }^{8}$ The Ghana Stock Exchange (GSE), the Nigerian Stock Exchange (NSE) and the Bourse Régionale des Valeurs Mobilières (BRVM).
} 
and Titman, 1998). In the Cameroonian financial market, for example, a normal-sized public offering can reduce the percentage of ownership of the owners of a newly introduced company from $60 \%$ to $15 \%$, which drastically reduces the control and decision-making power of the Board of Directors (Jebali, 2008). According to Maache (2007) in Morocco and Eyinga (2008) in Tunisia, the family character of companies is an obstacle to an IPO. In Cameroon, more than $80 \%$ of firms are familyowned.

Third, the costs associated with the IPO are a significant constraint. Generally, the IPO appears to be a process that generates direct and indirect costs (Ritter, 1987) for the candidate company. It is a delicate operation that also requires preparation, which generates costs (upgrading costs and commissions) for the candidate company. In absolute figures, Ritter (1987) estimates the average costs of the introduction at $\$ 250,000$ in the United States, which would correspond in Italy to about $3.5 \%$ of the capital raised according to Pagano et al. (1998) or to about $1 \%$ of the market capitalization in France (Jacquillat, 1994).

Most of the above-mentioned studies have been conducted in the European and American context. This reflects the novelty of this theme in the African context. Nevertheless, those who have taken an interest in it have not integrated aspects such as the stock market perception of company managers and the costs linked to access to the coast.

\subsection{Methodology for analyzing internal constraints}

This research follows a positivist logic based on a hypothetical-deductive analysis. The study population is made up of all the large companies constituted as Limited Companies (SA) present on the Cameroonian territory and the study sample is obtained using the convenience method.

The information was collected from 42 companies using a questionnaire. Closed and open questions were associated with each factor studied. The 5-level Likert scale was used. This primary data was collected in 2016 in the city of Douala, which is home to more than $75 \%$ of the companies in Cameroon.

To achieve the objectives set, three types of analyses are performed: flat sorting, factor analysis, more precisely Principal Component Analysis (in order to reduce the number of elements that capture the determinants of the IPO decision) and multiple econometric regression, which allows to explain the IPO decision by the different components retained by the factor analysis.

\subsection{Internal constraints on the reluctance to go public}

\subsubsection{Statistical analysis and reliability of the concept measurement scale}

The results of this survey reveal that $88.1 \%$ of the managers interviewed were aware of the existence of the financial market in Cameroon through two main channels: the press (52.6\%) and financial institutions (18.4\%). It appears that $40.5 \%$ consider it to be very important as a tool for the development of their business and to make themselves known. In addition, 38.1\% of the respondents emphasize the increase in capital and awareness, while $42.9 \%$ consider the transparency of the company as an advantage of the stock market compared to other sources of financing. However, $23.8 \%$ of the respondents find it very risky, although with the same frequency they think that this risk is not too important. On the other hand, $28.6 \%$ of the respondents perceive the possibility of having competitors in their capital and the risk of losing power in their company as an important factor for not going public. They also believe that cost is an important factor in their decision to go public. 
For the reliability analysis, Cronbach's Alpha was used and the results of the test show a largely acceptable internal consistency reliability (Cronbach's Alpha equal to 0.834).

\subsubsection{Results of the factorial analysis}

Principal component analysis (PCA) was performed to extract the most relevant items. The results are provided in Table 1.

Table 1: Summary of PCA results

\begin{tabular}{|c|c|c|}
\hline Concept & Dimensions obtained from PCA & Key statistics \\
\hline $\begin{array}{l}\text { The stock market } \\
\text { perception of } \\
\text { company managers }\end{array}$ & $\begin{array}{l}\text { Five dimensions: } \\
\text { 1-the stock market versus other funding } \\
\text { sources (BASF); } \\
\text { 2- role of the MF (ROB); } \\
\text { 3- advantage of the exchange (AVBO); } \\
\text { 4- reputation and transparency (NOTR); } \\
\text { 5- corporate image (EMI) }\end{array}$ & $\begin{array}{l}\text { Index of } \mathrm{KMO}=0,633 ; \\
\text { sig of bartlett = 0,000; } \\
\mathrm{VE}_{1}=19,844 \% \\
\mathrm{VE}_{2}=18,686 \% \\
\mathrm{VE}_{3}=15,546 \% \\
\mathrm{VE}_{4}=14,848 \% \\
\mathrm{VE}_{5}=9,480 \% \\
\mathrm{VET}=78,405 \% ; \alpha=0,726\end{array}$ \\
\hline $\begin{array}{l}\text { The loss of control } \\
\text { of power in the } \\
\text { company }\end{array}$ & $\begin{array}{l}\text { One dimension: } \\
\text { The loss of control over power in the } \\
\text { company (PECF) }\end{array}$ & $\begin{array}{l}\text { Index of } \mathrm{KMO}=0,658 \\
\text { sig of bartlett }=0,000 \\
\mathrm{VE}=67,383 ; \alpha=0,755\end{array}$ \\
\hline $\begin{array}{ll}\text { Loss } & \text { of } \\
\text { confidentiality } & \text { of } \\
\text { company } & \\
\text { information } & \\
\end{array}$ & $\begin{array}{l}\text { One dimension: } \\
\text { Loss of confidentiality of company } \\
\text { information (PECT) }\end{array}$ & $\begin{array}{l}\text { Index } \mathrm{KMO}=0,762 ; \\
\text { sig of bartlett }=0,000 ; \\
\mathrm{VE}=69,976 \% ; \alpha=0,854\end{array}$ \\
\hline $\begin{array}{l}\text { Costs related to the } \\
\text { IPO }\end{array}$ & $\begin{array}{l}\text { One dimension: } \\
\text { Costs related to the IPO (COUT) }\end{array}$ & $\begin{array}{l}\text { Index of } \mathrm{KMO}=0,714 ; \\
\text { sig of bartlett }=0,000 ; \\
\mathrm{VE}=66,396 ; \alpha=0,621\end{array}$ \\
\hline
\end{tabular}

Source: ourselves from SPSS results

It emerges that, of the 13 items measuring the stock market perception of company managers, only 10 were retained from the factorial analysis and grouped into 5 factors. Factor 1, made up of 3 items, was named the stock market in relation to other sources of financing (BASF) and explains $28.32 \%$ of the initial information; factor 2, also made up of 3 items, returns $18.60 \%$ of the initial information and was named the role of the stock market (ROB). It captures its usefulness and its importance for the development of the respondent's company; factor 3, made up of 2 items, was named advantages of the stock exchange (AVBO) and returns $13.647 \%$ of the initial information; factors 4 and 5, each made up of one item, explain respectively $9.66 \%$ and $8.16 \%$ of the initial information. They can be named respectively notoriety and transparency (NOTR) and company image (IME).

For the variable loss of confidentiality, the factor analysis extracted a single factor with an eigenvalue of 2.79 (encompassing all 4 items). It explains $69.97 \%$ of the total variance and can be interpreted as the risk of loss of confidentiality of business information (PECF).

In relation to the loss of control, the results allowed the extraction of a single factor with an eigenvalue equal to 2.02 and, explaining $67.38 \%$ of the total variance. This factor logically refers to the risk of loss of control (PECT) and encompasses all 3 items.

Finally, the factorial analysis allows us to admit the unidimensionality of the measurement scale of the variable costs related to the IPO, because it has extracted a single factor named cost (COUT) with an eigenvalue equal to 2.65 and explaining $66.39 \%$ of the total variance. 
Finally, taking into consideration these components retained by the factor analysis, the specific econometric model is written as follows:

$$
\mathrm{DIB}_{\mathrm{i}}=\beta_{0}+\beta_{1} \mathrm{BASF}_{\mathrm{i}}+\beta_{2} \mathrm{ROB}_{\mathrm{i}}+\beta_{3} \mathrm{AVBO}_{\mathrm{i}}+\beta_{4} \mathrm{NOTR}_{\mathrm{i}}+\beta_{5} \mathrm{IME}_{\mathrm{i}}+\beta_{6} \mathrm{PECF}_{\mathrm{i}}+\beta_{7} \mathrm{PECT}_{\mathrm{i}}+\beta_{8} \mathrm{COUT}_{\mathrm{i}}+\mu
$$

With DIB the IPO decision, measured by a set of questions that take into consideration the importance given to an IPO, and the possibility of opening its capital on the financial market.

The multi-collinearity analysis performed using the tolerance and variance inflation factor (VIF), shows the existence of a collinearity between the risk of loss of control (PECT) and the risk of loss of confidentiality of information (PECF). To avoid biasing the results, the PECT factor was eliminated during the estimation, knowing that it could be interpreted as a function of the PECF factor. Thus, the results of the econometric regression are presented in the following table:

Table 2: OLS parameter estimates

\begin{tabular}{|l|l|l|l|l|}
\hline \multirow{2}{*}{} & \multicolumn{4}{l}{ IPO decision } \\
\cline { 2 - 5 } & $\mathrm{B}$ & S.E & $\mathrm{T}$ & SIG. \\
\hline (Constant) & 2,922 & 0,149 & 19,630 & $0,000^{* * *}$ \\
\hline BASF & $-0,173$ & 0,207 & $-0,837$ & 0,415 \\
\hline CONC & 0,891 & 0,180 & 4,960 & $0,000^{* * *}$ \\
\hline AVBO & $-0,042$ & 0,169 & $-0,247$ & 0,808 \\
\hline NOTR & 0,264 & 0,148 & 1,784 & $0,093^{*}$ \\
\hline COPI & 0,036 & 0,204 & 0,177 & 0,862 \\
\hline PECF & $-0,052$ & 0,159 & $-0,328$ & 0,747 \\
\hline COUT & $-0,342$ & 0,187 & $-1,829$ & $0,086^{*}$ \\
\hline & $\mathrm{R}=0,855$ & $\mathrm{R}^{2}=0,732 \mathrm{R}^{2}$ ajusté $=0,614$ & \\
\cline { 2 - 5 } & $\mathrm{F}=6,233$ & Prob $=0,001^{* * *}$ & \\
\hline
\end{tabular}

$* * *, * * *$ significant at the $1 \%, 5 \%, 10 \%$ thresholds respectively.

\section{Source: SPSS}

The results contained in Table 2 reveal a positive value (2.92) and significant at the $1 \%$ threshold, of the constant, which highlights the unspecified factors. This significance shows that several other variables (stock market culture and financial literacy) can explain the decision to go public. Moreover, with the Fisher statistic, we conclude that the model used allows to explain significantly, at $73.20 \%$, the decision of the managers of the companies surveyed to go public.

In relation to the five (5) factors retained by the factorial analysis as capturing the stock market perception of company managers, we note that two (2) are significant. These are the factors "role of the stock market" and "notoriety and transparency", which are positive and significant at the thresholds of 1 and 10\% respectively. Thus, the more managers have a good perception of the stock market, the more they are in favor of taking their company public. This result is consistent with that obtained by N'dri and Aderomou (2011) in Benin and Bayala (2002) in Burkina Fasso.

The analysis of Table 2 above also shows that there is a negative and non-significant relationship between the risk of loss of confidentiality of company information and the decision to go public. This means that, without being significant, the fact that the firm is obliged to publish information related to its management at the time of and after the opening of its capital prevents managers in Cameroon from listing their firm on the financial market. This result is consistent with those of Bernoussi (2012). Furthermore, Campbell (1979), Pagano et al. (1998), Yosha (1995), and Eyinga (2008) also cited the risk of losing confidentiality as a factor of reluctance to go public. In the context of this study, the non- 
significance of this result can be explained by the small sample size because in the same context, but with 97 firms Tchapga and Feudjo (2016) found a significant relationship.

Since the risk of loss of control is correlated with the risk of loss of confidentiality, we can deduce that DIB is also negatively related to the possibility of managers losing control of their firm in the sense of Pagano et al. (1998).

As far as cost is concerned, the information in the previous Table 2 shows that it has a negative and significant effect at the $10 \%$ threshold on the IPO decision. This result reveals that the higher the costs related to the IPO, the less managers will make the decision to list their company. This finding is consistent with those of Yosha (1995), Barbaret (1990), Pagano et al (1998), Ritter (1987) and Eyinga (2008).

In summary, the costs associated with an IPO are the main obstacle to making this decision. Moreover, while these variables are related to the manager's point of view, several other variables are related to the financial market environment.

\section{External constraints}

Several variables related to the financial market environment can have an impact on its development. In this paper we highlight those that are likely to negatively influence the development of the Cameroonian financial market. This analysis is based on the literal, factual study, but especially on the analysis of open-ended responses (verbatim) obtained from the previous questionnaire. In fact, in the questionnaire used, an open-ended question was asked of business leaders in order to gather their views on the external factors that would reduce the possibility for them to take advantage of the financing offered on the financial market. It is the statistics on these issues that are discussed in this section. Constraints identified include: financial culture, the socio-political-economic environment (the business climate), the legal-institutional framework, and the characteristics of firms and financial market participants.

\subsection{The weak stock market culture of financial market participants}

Financial literacy plays a major role in the development of the financial system. In Cameroon, however, the low rate of bank penetration and the important role of financial institutions in the development of the financial market help to explain the quality of this market. This low level of banking is characterized by human factors such as mistrust and lack of knowledge of financial culture (Bebey, 2010). Moreover, we know that that the efficiency of the financial market is linked to that of the banking system. Consequently, a low level of banking is linked to a low level of stock market culture (lack of knowledge of the functioning and opportunities of the stock market), the latter constituting a very important blocking factor to the opening of the capital.

On this subject, Maache (2007) shows that one of the constraints that explains the reluctance of Moroccan companies to be listed on the stock market is the lack or absence of a stock market culture among their managers. According to him, the problem of companies in most African countries is not financing per se, but the way they are financed, because managers prefer bank financing rather than popular shareholding. This practice is shared by COSUMAF officials who argue that the financial culture in the CEMAC subregion is still embryonic and that it also constitutes an obstacle to opening up the capital of Algerian (Yazid, 2016), Burkinabe (Bayala, 2002) and Senegalese (Soleil, 2015) companies to the public.

In the framework of this study, $12.79 \%$ of the company managers interviewed indicated that the decision to list their company on the Cameroon stock exchange was negatively related to the quality of the financial culture or education of the various players. They justify this by the nature of the financial 
education of the players, a lack of information or simply a concern for financial communication. Indeed, of all the responses obtained by verbatim, the problem of communication about the financial market was the one most mentioned (51\%) as a factor of reluctance to open up capital. To date, it must be noted that few awareness and training actions have been carried out in order to improve the stock market culture and to allow its popularization to all actors.

Thus, financial education constitutes one of the important factors of reluctance, which hinders the development of the financial market, among several others.

\subsection{The unattractive business climate}

\subsubsection{Economic constraints to financial market development in Cameroon}

The Cameroonian economic context is characterized by an unattractive business environment that hinders the competitiveness of companies and the attraction of investors, whose role is major. Indeed, the General Census of Enterprises conducted by the INS (2009) shows that $54.5 \%$ of business leaders have a poor opinion of the business environment in Cameroon, which is not conducive to the development of their activities at several levels. Similarly, the Business Climate Survey report (2011) states that several factors (70\% of which are administrative procedures) are the main obstacles to investment. The business leaders interviewed specifically for this study argue that these factors have negatively impacted their business, regardless of their size. For them, the economic environment of the country (12.19\%), government policy (14.63\%), or the fiscal policy adopted by Cameroon (21.95\%), are the main constraints that hinder their decision to resort to financing the financial market.

\subsubsection{Socio-political constraints}

According to Murinde (2013), the political environment has a crucial influence on financial markets, on their ability to play the main role and even more so for the economies of developing countries. The Cameroonian environment in fact, is characterized by high political, social tension and very advanced corruption.

In Cameroon, uncertainty about the political future, due to its structure and organization on the one hand, and on the other, the fight against the terrorist sect in the north of the country, various corporatist claims and corruption, are at the origin of a social insecurity that increases its country risk. This situation is likely to discourage investment and reduce the arrival of international investors on the financial market, which is becoming very risky. In this regard, the Business Climate Survey report (2011) indicates that $60 \%$ of business leaders in Cameroon recognize insecurity as a factor reducing the development of their structures, in addition to the financial constraints that weigh on them (ILO, 2012). These two reports also indicate that 50.6 percent (BCS) and 75 percent (ILO) of respondents believe that corruption is responsible for the deterioration in the quality of the business environment in Cameroon.

The business climate in Cameroon is therefore a significant obstacle to the development of its financial market. In fact, $7.3 \%$ of the managers interviewed put forward political and socio-economic insecurity as the reason for their reluctance to open up their capital. This is the reason why African capital markets remain underdeveloped, narrow and illiquid. According to Dahou et al (2009), the consequence is limited access to long-term financing and reduced capacity for these countries to finance themselves through local debt. 


\subsubsection{Characteristics of firms and the profile of actors}

According to Jacquet and Pollin (2012), the general characteristics of firms, notably their financial structure, maturity, size and sector of activity, are also explanatory variables for the development of the financial market. Thus, the smaller and more entrepreneurial the firm, the less developed the financial market will be. However, in Cameroon, out of more than 93,000 companies listed by the INS (2009), less than $1 \%$ are large companies. This is the reason why $12.19 \%$ of the managers surveyed for this article mentioned that the mismatch between the listing conditions and the size of their company is one of the reasons why they are reluctant to open up the capital of their company. Indeed, the share compartment dedicated to SMEs is not yet functional.

Moreover, according to the INS (2009), more than $80 \%$ of the businesses in Cameroon are familyowned and operated. Bouba (2010) points out that this type of company is very reluctant to open their capital to the public, unlike companies with a diversified Board of Directors. The views of the managers surveyed for this study reflect the truth of these findings in Cameroon. Indeed, $14.63 \%$ of them believe that the family structure of companies in Cameroon is one of the reasons that justify the reluctance to open their capital on the financial market. This can be explained by the fact that selffinancing is the primary source of financing in Cameroon.

Another explanation is associated with the profile of the various actors involved in the operation of the financial market and more specifically, their low professionalism. Indeed, the lack of expertise and human resources (capable of mastering the operation, management and understanding of the financial market), which characterizes Africa in general and Cameroon in particular, is a significant obstacle to the decision to go public (Bouba, 2010). Thus, 21.93\% of the company managers interviewed believe that the lack of competence of the actors involved is one of the reasons for their lack of interest in the stock market.

In addition to the characteristics of the company in Cameroon and the competence of the actors, constraints that weigh on the possibility for them to open their capital on the financial market in Cameroon, we also distinguish the effect of the legal-infrastructure framework.

\subsubsection{Legal and institutional constraints}

It is well known that an efficient financial system requires strong institutions and a well-established legal framework. According to Dahou et al (2009), the protection of property and consumer rights, contract enforcement laws, and corporate governance are essential ingredients to deepen the financial market and create a conducive business environment.

\subsubsection{The legal and regulatory framework}

An efficient financial system depends on an efficient legal system. In relation to the financial market, the regulatory framework concerns the obligation of information to which companies are subject towards investors, the possibility of contesting the decisions of managers or majority shareholders before the competent courts, the status and scope of the power of the regulatory authority, its independence and the sanctions it imposes.

This link between law (legal infrastructure) and finance therefore poses a serious problem for the development of the financial market in Cameroon. Indeed, despite the coexistence of an Anglo-Saxon legal system ("Common Law") and a continental European legal system (France, Germany), the latter takes precedence over the "Common Law" system. According to Jacquet and Pollin (2012), the AngloSaxon legal system facilitates access to financing through the financial market, because it better protects the providers of capital. Moreover, it is more flexible and better suited to innovation. 
In Cameroon, the financial market is governed and organized by a law promulgated on December 22, 1999 by the President of the Republic, who appoints the Director of the DSX and the CMF. Moreover, the companies that have opened their capital to it are essentially parastatals, where the State is a partial owner. These facts demonstrate the dependence of the Cameroonian financial market on the State, which constitutes a factor of reluctance to access the market and justifies the fact that 19.4 percent of the company managers interviewed believe that the regulatory framework, legal security, the guarantee of confidence and the dependence of the financial market in Cameroon on the law constitute a significant brake on the decision to open their capital.

\subsubsection{Institutional constraints}

In Cameroon, as in most African countries, the financial infrastructure is in the early stages of development. Moreover, these institutions suffer from a lack of innovative financial instruments (Chanel-Reynaud and Chabert, 2005) and are essentially stock markets, in the sense that only the cash segment really works.

Moreover, while from an institutional point of view, the payment system and the regulator seem to exist and function, one of the problems slowing down the take-off of the financial market in Cameroon is the absence of market makers and the quality of investors. Indeed, there are no real investors in the Cameroonian financial market. The Mutual Funds (FCP) and Investment Companies with Variable Capital (SICAV), provided for the creation of the financial market of Cameroon, are not yet functional. It is the associated banks that play the role of investment service providers, despite the law of June 12, 2016, promulgated by the President of the Republic of Cameroon and governing UCITS and ISPs on its financial market. This means that in Cameroon, it is institutional investors, which dominate individual investors. According to Bouba (2010), the absence of the latter explains the low level of subscription by individuals.

\section{Conclusion}

The main objective of this study was to identify the factors that explain the reluctance of companies in Cameroon to open their capital on the financial market. The different analyses carried out allow us to conclude that business leaders in Cameroon have a positive perception of the stock market. This means that they consider it as a credible financing opportunity, essential for the development of their structure and the improvement of their reputation. Nevertheless, they are reluctant to go public and the main reasons are related to both the perception of business leaders and the environment of the market company considered.

Internally, the most important constraint is the cost, which negatively and significantly influences the decision to go public. In other words, company managers consider that the costs of opening their capital to the financial market are high. However, half of the managers interviewed stated that they were prepared to bear a cost equal to no more than $0.5 \%$ of the amount raised on the stock market. By reducing the amount of intermediaries' commissions, which are very high in Cameroon, the costs of going public will decrease and this could lead to a greater number of companies being listed. The risk of losing the Confidentiality of information and control of their company are other internal factors that slow down the opening of their capital to the financial market.

At the environmental level, the constraints identified include a weak financial culture, the country's socio-political and economic environment, the legal and institutional framework and the characteristics of the companies. The coexistence of two financial markets and the complexity of the tax system have also long been factors of reluctance to an IPO in Cameroon. These factors also 
explain the low mobility of listed securities. Thus, we realize that the Cameroonian economic environment has not been prepared to encourage companies to open their capital. This is all the more so since one of the conditions for opening up capital in this financial market is the presentation of financial statements for the last three (3) years. However, the INS notes in its 2012 report that less than $13 \%$ of companies in Cameroon keep formal accounts.

The companies interviewed also mention the problem of communication of the stock market. Indeed, according to the managers, the communication tools and the pedagogy usually used on the financial market in Cameroon, have not been of a nature to attract the audience of companies. Hence the need to revitalize communication by raising awareness among business leaders in Cameroon on the usefulness and challenges of the financial market, through seminars and conferences. The financial market in Cameroon could also create a service in charge of assisting companies wishing to go public, by providing them with the necessary advice and expertise for the preparation of this operation.

\section{REFERENCES}

[1] Afego P., "Market Efficiency in Developing African Stock Markets: A Survey And Review Of Literature", Social Sciences Research Network 1909732, 2011.

[2] Barbaret C., "introductions to the secondary market: caracteristics and costs evaluation", doctoral thesis, university of Paris-Dauphine, 1990.

[3] Bayala B., "the regional stock exchange in west africa, the IPO: why and why not?", companies and investors, doctoral thesis, Center For Development Studies-University of Groningen-Netherlands, 2002.

[4] Bernoussi A., "head bank, banking syndicate and IPO : application to the european stock market", doctoral thesis, University Lille 2, 2012.

[5] Bouba Z., "the CEMAC financial market: case the BVMAC", ISCTE business School, Instituto Universitario de Lisboa, Master memory, 2010.

[6] Campbell T., "Optimal Investment Financing Decisions and the Value of Confidentiality", Journal of Financial and Quantitative Analysis, Vol.14, n5, 1979, pp. 913-924.

[7] Chanel-Reynaud G. et Chabert D., "european financial infrastructure, basis of an integrated financial space", financial economy journal, $\mathrm{N}^{\circ} 2$, vol 79, 2005, pp. 289-308

[8] Dahou K., Omar H. I., Pfister M., "Develop financial markets for growth and investment", report of the ministerial meeting and expert round table, 2009.

[9] Ekpe A., "multiple listing in africa : ECOBANK's succesful experience", private sector and development, proparco review, 2010.

[10] Eyinga E. M., "the IPO and its effect on the value of company: empirical investigation in the Tunisian context", economy and finance, 2008.

[11] Jacquet P. et Pollin J. P., “ financial system and growth”, financial economics journal n 106, 2012, p77-110

[12] Jacquillat B., "IPO: what do i know ? ”, PUF, $2^{\circ}$ edition, 1994.

[13] Jebali A., "SMEs and stock exchange listing: is the company right to consider it ?", research, economy and finance, 2008.

[14] Jegadeesh, N., Weinstein, M., Welch, I., "An empirical investigation of IPO returns and subsequent equity offerings", Journal of Financial Economics 34, 1993, P153- 175.

[15] Maache A., "IPO case of BVC", research paper, Economy and Finance, 2007.

[16] Murinde V., "financial markets : roles and challenges", paper presented at the international conference on accelerating africa's development five years after entering the XXI ${ }^{\mathrm{e}}$ century, 2013.

[17] Mussoka P., “camerounian small and medium enterprises”, Denis \& Lenora Foretia Foundatio, 2013.

[18] Modigliani F. and Miller M., "Corporate Income Taxes And The Cost Of Capital: A Correction”, American Economic Review, 53 (3), 1963, pp. 433-443.

[19] Myers S. C. et Majluf N. S., "Corporate Financing And Investment Decision When Firms Have Information That Investor Do Not Have", journal of financial economics, Vol. 13, 1984, p187-221.

[20] N'dri L. K. et Aderomou R. B., " the IPOs at the BRVM : Theories and Analysis of the case of unlisted companies in Benin”, ISSN: 16941225, 2011.

[21] Nkontchou C., " the recent rise of african financial markets", private sector and development, proparco review, 2010.

[22] Pagano M. and Panetta F., Zingales L., "Why Do Companies Go Public? An Empirical Analysis", the Journal Of Finance, Vol LIII, n ${ }^{\circ} 1,1998$. 
[23] Rajan R., Servaes H., et Zingales L., "The Cost of Diversity: The Diversification Discount and Inefficient Investment", The Journal of finance, vol. lv, no. 1, February 2000

[24] Ritter, J., R., “The Cost of Going Public”, Journal Of Financial Economics 19, 1987, p269-281.

[25] Standley S., "what are the determinants of the development of financial markets in sub-saharan Africa? ", private sector and development, proparco review, 2010.

[26] Tchapga D. C. C. et Feudjo J. R. "stock exchange listing and the problem of financing companies in a developing economy", Management and strategy review, (1:9), 2016 p1-19.

[27] Yartey C. A. et Adjasi C. K., Stock Market Development In Sub-Saharan Africa: Critical Issues and Challenges", International Monetary Fund Working Paper WP/O7/209, 2007.

[28] Yosha O., "Information Disclosure Cost and The Choice Of The Financing Source", Journal Of Financial Intermediation 4, 1995, p3-20.

[29] Zingales L., "Insider Ownership And The Decision To Go Public", The Review of Economic Studies, Vol. 62, 1995, p425-448. 